\title{
Asthma control score based on filled medication prescriptions: A validation study
}

\author{
Marie-France Beauchesne PharmD 1,2,3, Amélie Chartier BPharm MSc ${ }^{4}$, Anne Fillion BPharm MSc ${ }^{2}$, \\ Catherine Lemière $\mathrm{MD} \mathrm{MSc}{ }^{2}$, Sophie Lecompte ${ }^{2}$, Lucie Blais $\mathrm{PhD}^{1,2,3}$
}

M-F Beauchesne, A Chartier, A Fillion, C Lemière, S Lecompte, L Blais. Asthma control score based on filled medication prescriptions: A validation study. Can Respir J 2008;15(8):423426.

BACKGROUND: Periodic measurement of disease control is recommended to characterize asthma and monitor treatment.

OBJECTIVE: To elaborate and validate an asthma control score (ACS) for use in studies based on administrative health databases. METHODS: Adult patients with asthma were recruited from a clinic. The ACS is based on the average number of doses of short-acting inhaled beta 2 -agonists taken per week and short courses of oral corticosteroids dispensed over a three-month period. Data were obtained from the Régie de l'assurance maladie du Québec database in Canada. The ACS was compared with the asthma control questionnaire and the use of health care services for asthma over a 12-month period.

RESULTS: A total of 60 patients were enrolled. They had a mean ( \pm SD) age of $50.4 \pm 13.9$ years, and $43.3 \%$ were male. Patients had had asthma for $20.8 \pm 15.1$ years on average and had a mean prebronchodilator forced expiratory volume in $1 \mathrm{~s}$ of $77.0 \%$ of the predicted value. The mean ACS was $8.3 \pm 11.6$, with a range of 0 to 60 . The ACS was not found to be correlated with the asthma control questionnaire, but it was significantly associated with health care services used. For each additional point in the ACS, patients were $2 \%$ more likely to need acute care for asthma (rate ratio 1.02; $\mathrm{P}=0.02$ ).

CONCLUSIONS: Further studies including patients followed by general practitioners are required before the general use of this score. This innovative score is useful to rapidly assess the control of asthma over long periods of time and at a low cost in studies using administrative drug databases.

Key Words: Asthma; Asthma control; Asthma control score; Prescription drug database; Validation

\section{L'indice de contrôle de l'asthme d'après la délivrance des ordonnances de médicaments : Une étude de validation}

\begin{abstract}
HISTORIQUE : La mesure périodique du contrôle de l'asthme est recommandée afin de la caractériser et d'en surveiller le traitement. OBJECTIF : Mettre au point et valider un indice de contrôle de l'asthme (ICA) à utiliser dans les études d'après des études de bases de données administratives de santé.
\end{abstract}

MÉTHODOLOGIE : Les auteurs ont recruté des patients asthmatiques adultes dans une clinique. Ils ont fondé l'ICA sur le nombre moyen de doses de béta 2 -agonistes en aérosol à action brève prises par semaine et sur les traitements de corticoïdes par voie orale de courte durée dispensés sur une période de trois mois. Ils ont obtenu leurs données dans la base de données de la Régie de l'assurance-maladie du Québec, au Canada. Ils ont comparé l'ICA au questionnaire sur le contrôle de l'asthme et au recours à des services médicaux pour l'asthme au cours d'une période de 12 mois. RÉSULTATS : Au total, 60 patients ont participé à l'étude. Ils avaient un âge moyen ( $\pm E ́ T)$ de 50,4 $\pm 13,9$ ans, et 43,3\% étaient de sexe masculin. Les patients étaient asthmatiques depuis une moyenne de $20,8 \pm 15,1$ ans et présentaient un volume expiratoire maximal par seconde de 77,0 \% de la valeur prédite. L'ICA moyen était de $8,3 \pm 11,6$ ans, avec une plage de 0 à 60. Ils n'ont pas pu corréler l'ICA avec le questionnaire sur le contrôle de l'asthme, mais l'ont associé de manière significative avec les services de santé utilisés. Pour chaque point supplémentaire à l'ICA, les patients étaient $2 \%$ plus susceptibles d'avoir besoin de soins aigus de l'asthme (ratio des taux de 1,$02 ; \mathrm{P}=0,02$ ).

CONCLUSIONS : Il faudra mener d'autres études incluant des patients suivis par des omnipraticiens avant de généraliser l'utilisation de cet indice. Cet indice novateur est utile pour évaluer rapidement le contrôle de l'asthme à long terme et à faible coût dans le cadre d'études faisant appel à des bases de données administratives de médicaments.

\begin{abstract}
sthma is a respiratory disease that affects more than $8 \%$ of Athe Canadian population aged 12 years and older (1). In 1990, the total costs associated with asthma were estimated to be over 600 million Canadian dollars (2). Asthma control is still suboptimal despite better understanding of the management of this disease. A Canadian survey (3) conducted in 1999 demonstrated that $60 \%$ of the asthmatic patients did not have their asthma controlled according to Canadian asthma guidelines.

The most recent Global Initiative for Asthma guidelines report that the classification of asthma by severity is most useful before initiating treatment (4). Once the treatment has been initiated, they recommend a periodic assessment of the level of

asthma control to monitor the response to therapy (4). Most emphasis is now being placed on strategies to achieve asthma control and on the need for a valid measure of these strategies. Several definitions of asthma control reported in the literature have been based on the occurrence of asthma symptoms during a period of time (5); the clinical deterioration caused by the disease (6); the combination of asthma severity, management and adherence to treatment (5); and the absence or minimal need for inhaled short-acting beta 2 -agonists (7). Cockroft and Swystun (7) have reported that asthma control can be achieved in the absence or presence of minimal symptoms, regardless of the medication taken by the patient.
\end{abstract}

${ }^{1}$ Faculty of Pharmacy, University of Montreal; ${ }^{2}$ Hôpital du Sacré-Coeur de Montréal, Montréal, Québec; ${ }^{3}$ Endowment Pharmaceutical Chair AstraZeneca in Respiratory Health; ${ }^{4}$ Department of Pharmacy, McGill University Health Centre, Montreal, Quebec

Correspondence: Dr Marie-France Beauchesne, Faculty of Pharmacy, Hôpital du Sacré-Coeur de Montréal, 5400 Boulevard Gouin Ouest,

Montréal, Québec H4J 1C5. Telephone 514-338-2222 ext 2666, fax 514-338-3200, e-mail marie-france.beauchesne@umontreal.ca 


\section{TABLE 1}

\section{Definition of the asthma control score}

\begin{tabular}{lc}
\hline Over a three-month period & Score \\
\hline Three or less doses of inhaled short-acting beta -agonists per week $_{2}$ & +0 \\
Each additional dose of inhaled short-acting beta & -agonists per week \\
Each short course of oral corticosteroids & +1 \\
\hline
\end{tabular}

In studies involving asthma patients, investigators have to adequately categorize the control of asthma $(7,8)$. Questionnaires are available to assess asthma control $(5,6,9)$, but only a few have been adequately validated. In these questionnaires, asthma control is determined according to symptoms $(5,6)$, pulmonary function (6), health care use $(7,10)$ and/or medication consumption (9).

Epidemiological studies using administrative databases are increasingly being used in the field of asthma. Although these databases include data on thousands of patients regarding prescribed medications and refills, they do not include any data on clinical and functional parameters. Therefore, an asthma control score (ACS) based only on the consumption of prescribed medications would be useful for observational and clinical studies using administrative databases. Thus, the aim of the present study was to elaborate and validate an ACS based only on asthma medications prescribed and dispensed at community pharmacies.

\section{Study population}

\section{METHODS}

Asthma patients were recruited from the outpatient asthma clinic of the Hôpital du Sacré-Coeur de Montréal (HSCM) (Montreal, Quebec) between January and March 2003. Patients were included in the study if they were 18 years of age or older, were followed at the asthma clinic for at least two years, had an asthma diagnosis confirmed by pulmonary function tests assessed by a respiratory physician, were covered by the provincial drug insurance plan or by a private drug insurance plan, and obtained their prescribed medications from only one pharmacy during the 12 -month period preceding recruitment. Patients were excluded if they did not speak English or French, had a chronic obstructive pulmonary disease (confirmed by pulmonary function tests), work-related asthma, pulmonary cancer or dementia, or had an inflammatory disease needing regular treatment with oral corticosteroids. The research protocol was approved by the HSCM ethics committee, and participating patients signed a written informed consent form.

\section{Patient interview and data collection}

Patients were interviewed by a pharmacist to gather information on sociodemographic variables, drug insurance plan, duration of asthma and cigarette smoking, as well as unscheduled medical visits, emergency department visits and hospitalizations for asthma in the previous 12 months. At the end of the interview, the patient had to complete an asthma control questionnaire (ACQ) to measure asthma control during the previous week (6). During the interview, the investigator also obtained permission from the patient to have access to his or her pharmaceutical drug profile from the Régie de l'assurance maladie du Québec (RAMQ) database for patients covered by the RAMQ drug insurance plan, or directly from the pharmacy for patients covered by a private drug insurance plan, to have access to data related to medications dispensed at community pharmacies. For all patients, data were obtained on all medications (drug name, dose, dosage form, quantity dispensed and duration of the prescription) dispensed in the three months preceding the interview. Access to the RAMQ data was obtained from the Commission d'accès à l'information du Québec, and the protocol was approved by the HSCM ethics committee. The patient's medical chart was also reviewed by a pharmacist to collect information on pulmonary function tests.

\section{Medication-based ACS}

Based on asthma medications dispensed at community pharmacies over a three-month period, the ACS, a score to measure the control of asthma, was developed. The ACS was based on the average number of doses of short-acting inhaled beta agonists taken per week and short courses of oral corticosteroids dispensed during the three months preceding the interview. The weekly number of doses of short-acting inhaled beta $2^{-}$ agonists was estimated using an algorithm based on the name and the dose of the prescribed medication, the duration of the prescription, the quantity of drug dispensed and the dates of prescription renewals. The ACS has a lower limit of 0 (very good control). However, it does not have a predefined upper limit because the greater the use of rescue medications, the higher the score. Consequently, the higher the ACS, the higher the level of uncontrolled asthma. The ACS is described in detail in Table 1. As an example, for a patient who used seven doses of short-acting beta 2 -agonists per week in the previous three months, and no course of oral corticosteroids, his or her ACS would be $4(7-3=4$ additional doses of inhaled short-acting beta $_{2}$-agonists per week).

\section{Validation of the ACS}

For validation purposes, the ACS was correlated with the ACQ and the use of health care services. The ACQ is a score that was developed and validated for research purposes by Juniper et al (6). The ACQ measures asthma control over the previous week and is based on seven questions related to asthma symptoms, the use of short-acting inhaled beta 2 -agonists, and the prebronchodilator forced expiratory volume in $1 \mathrm{~s}\left(\mathrm{FEV}_{1}\right)$. The ACQ varies from 0 (very good control) to 6 (extremely poor control). Finally, the association between the ACS and the use of health care services (the number of unscheduled medical visits, emergency department visits and hospitalizations for asthma) reported by the patient over the 12-month period preceding the interview was investigated.

\section{Statistical analysis}

Means and proportions were used to describe the characteristics of the study patients. The correlation between the ACS and the ACQ was assessed using Spearman's correlation. The association between the ACS and the use of health care services was assessed using a Poisson regression model, which provided an estimate of the rate ratio of use of health care services per unit change in the ACS.

\section{RESULTS}

In total, 407 patients were screened at the asthma outpatient clinic and 260 patients did not fulfill the selection criteria. From the 147 eligible patients, one patient refused to participate and 86 were not referred to the investigators by the respiratory physicians; thus, the study population was formed from 
TABLE 2

Patient charateristics $(n=60)$

\begin{tabular}{|c|c|}
\hline Characteristic & \\
\hline Age, years, mean $\pm S D$ & $50.4 \pm 13.9$ \\
\hline Male patients, n (\%) & $26(43.3)$ \\
\hline Duration of asthma, years, mean \pm SD & $20.8 \pm 15.1$ \\
\hline Smokers, n (\%) & $6(10.0)$ \\
\hline Pack-years, mean \pm SD & $11.5 \pm 5.0$ \\
\hline Ex-smokers, n (\%) & $21(35.0)$ \\
\hline Pack-years, mean \pm SD & $20.4 \pm 13.4$ \\
\hline \multicolumn{2}{|l|}{ Comorbidity, n (\%) } \\
\hline Allergic rhinitis & $45(75.0)$ \\
\hline Gastro-oesophagial reflux & $21(35.0)$ \\
\hline Acetylsalicylic acid allergy & $10(16.7)$ \\
\hline \multicolumn{2}{|l|}{$\mathrm{FEV}_{1}$ prebronchodilator, $\%$ predicted, $\mathrm{n}(\%)$} \\
\hline$>80$ & $30(50.0)$ \\
\hline $60-80$ & $24(40.0)$ \\
\hline$<60$ & $6(10.0)$ \\
\hline $\mathrm{FEV}_{1}$ prebronchodilator, $\%$ predicted, mean $\pm \mathrm{SD}$ & $77.0 \pm 17.3$ \\
\hline \multicolumn{2}{|l|}{ Prescribed antiasthmatic medication } \\
\hline Inhaled corticosteroids, n (\%) & $59(98.3)$ \\
\hline Dose in beclomethasone-CFC, $\mu \mathrm{g}$, mean $\pm \mathrm{SD}$ & $1817 \pm 1257$ \\
\hline Long-acting inhaled beta ${ }_{2}$-agonists, n (\%) & $46(76.7)$ \\
\hline Antileukotriene, n (\%) & $10(16.7)$ \\
\hline Theophylline, n (\%) & $12(20.0)$ \\
\hline Asthma control questionnaire score, mean $\pm \mathrm{SD}$ & $1.55 \pm 1.03$ \\
\hline
\end{tabular}

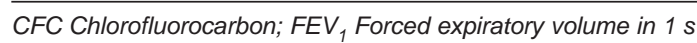

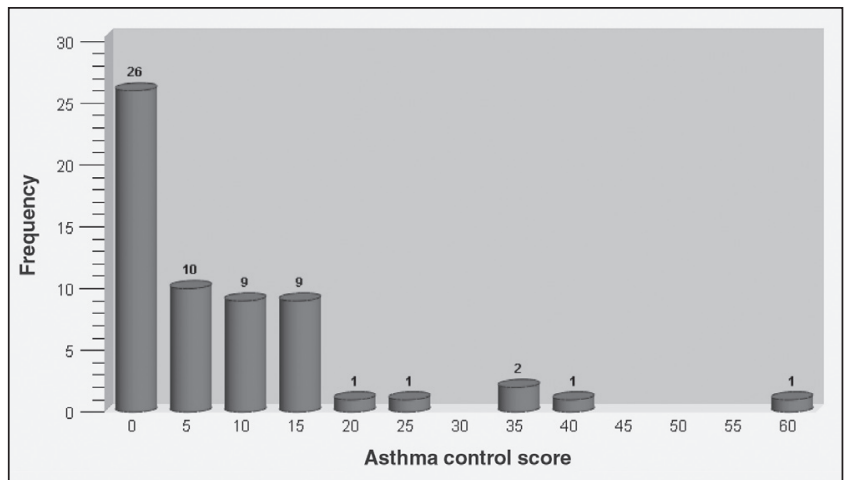

Figure 1) Distribution of the asthma control score $(n=60)$

the 60 asthma patients. Patient characteristics are presented in Table 2. Patients had a mean $( \pm S D)$ age of $50.4 \pm 13.9$ years, and $43 \%$ were male. Patients had had asthma for $20.8 \pm 15.1$ years on average, and $10 \%$ of patients were still smoking cigarettes at the time of the interview. At the time of the interview, patients had a mean prebronchodilator $\mathrm{FEV}_{1}$ of $77.0 \%$ of the predicted value, and $50 \%$ of them had an $\mathrm{FEV}_{1}$ below $80 \%$ of the predicted value. The average prescribed dose of inhaled corticosteroids recorded in the patient's medical chart was $1817 \pm 1257 \mu \mathrm{g}$ per day in beclomethasone-chlorofluorocarbon equivalent.

\section{The ACS}

On average, study patients had an ACS of $8.3 \pm 11.6$, with a range of 0 to 60 and a median of 4.0. Figure 1 shows that the
TABLE 3

\begin{tabular}{lc} 
Use of health care services for asthma one year preceding \\
the interview, among all asthmatic patients $(\mathbf{n}=60)$ \\
\hline \multicolumn{1}{l}{ Health care services for asthma } & $\mathbf{n}(\%)$ \\
\hline Emergency department visits & \\
0 & $51(85.0)$ \\
1 & $4(6.7)$ \\
$2-5$ & $5(8.3)$ \\
Hospitalizations & \\
0 & $55(91.7)$ \\
$\geq 1$ & $5(8.3)$ \\
Unscheduled medical visits & \\
0 & $45(75.0)$ \\
1 & $12(20.0)$ \\
2 & $3(5.0)$ \\
Total & \\
0 & $37(61.7)$ \\
1 & $12(20.0)$ \\
2 & $7(11.7)$ \\
$3-6$ & $4(6.7)$ \\
\hline
\end{tabular}

TABLE 4

Validation analyses for the asthma control score (ACS) $(n=60)$

\begin{tabular}{lcc}
\hline & Spearman's correlation or RR & P \\
\hline ACQ & 0.16 & 0.21 \\
Health care services for asthma & $1.02^{\star}$ & 0.02 \\
\hline
\end{tabular}

${ }^{*} R R$ Rate ratio per unit change in the ACS. ACQ Asthma control questionnaire

distribution of the ACS is skewed with $43.3 \%$ of the patients having a score of $\mathrm{O}$, indicating very good asthma control.

ACQ and use of health care services

Patients had on average an ACQ of 1.55, which indicates that the study population had controlled asthma with some persistent symptoms (Table 2). The distribution of the use of health care services in the year preceding the interview is presented in Table 3. In total, $38.3 \%$ of patients needed acute care during the 12 -month period under study: $25 \%$ had at least one unscheduled medical visit, $15 \%$ visited the emergency department and $8.3 \%$ were hospitalized for asthma.

\section{Validity of the ACS}

The results of the validation analyses are presented in Table 4 . The ACS was not found to be significantly correlated with the ACQ, but was found to be significantly associated with the need for acute care for asthma. For each additional point in the ACS, patients were $2 \%$ more likely to need acute care for asthma (rate ratio $1.02 ; \mathrm{P}=0.02$ ).

\section{DISCUSSION}

The present study intended to elaborate and validate an ACS based on information about asthma prescribed medications obtained from administrative and pharmacy databases. Only 60 of the planned 120 patients were enrolled in the present study. This could be partly explained by the restriction, set by our ethics committee, that trial participation had to be offered 
by physicians and not by the investigator. Approximately 86 patients who met the inclusion criteria and attended their appointment at the asthma clinic were not referred to the investigator by the respiratory physicians. The number of patients recruited, however, is similar to those in previous studies on this topic $(2,11)$.

A correlation between the ACS and the ACQ was not observed in our study. The ACQ is a validated score that is frequently used because it is simple and rapid (6). This result could be explained by under-use of short-acting beta -agonists $_{2}$ by the patients in the presence of asthma symptoms. In fact, many patients underestimate and tolerate their symptoms. Furthermore, the control of asthma varies over time, and the ACQ is based on a measure of asthma control over a oneweek period, whereas our ACS was based on a three-month period. To investigate the influence of the length of the observation period, we calculated the ACS for a shorter period of one month; however, the result remained the same. The ACS can thus be seen as a tool that can measure chronic lack of control, while the ACQ can better measure short-term lack of control.

On the other hand, the ACS was found to be associated with the use of health care services for asthma. However, a limitation associated with this result exists because patients had to recall their health care use over a one-year period. Similar results were obtained by Vollmer et al, (5) who had established a relationship among asthma control (using the Asthma Therapy Assessment Questionnaire) in the previous four weeks, health care use for asthma in the preceding year, and quality of life. In addition, Van Ganse et al (12) demonstrated that poor asthma control was associated with greater use of health care services. To the best of our knowledge, the ACQ has not been correlated with the use of health care services.

Limitations of our study include the low number of patients who used health care services and the retrospective nature of data collection. Furthermore, because oral corticosteroids may be used at treatment initiation in newly diagnosed patients to gain prompt control of asthma, this marker could also be associated with the severity, rather than only the control of asthma.

In our study, a simple score, the ACS, based on filled prescriptions of asthma medications, was developed to evaluate the control of asthma. In summary, the ACS was found to be correlated with health care use for asthma but not with the ACQ. Further studies with a greater number of subjects, who are followed by general practitioners for their asthma, are required before the general use of this score. This innovative score could potentially be used in the future to rapidly assess the control of asthma over long periods of time and at a low cost in clinical and epidemiological studies using administrative drug databases.

FUNDING: Drs Lucie Blais and Catherine Lemière are recipients of a New Investigator salary support grant from the Canadian Institutes for Health Research (CIHR). This study was funded by GlaxoSmithKline.

\section{REFERENCES}

1. Statistiques Canada. Personnes ayant de l'asthme selon le sexe, par province et territoire. <http://www.statcan.ca/francais/Pgdb/ health50a_f.htm> (Page consultée le 2 juin 2003).

2. Krahn MD, Berka C, Langlois P, et al. Direct and indirect costs of asthma in Canada, 1990. CMAJ 1996;154:821.

3. Chapman KR, Ernst P, Greenville A, Dewland P, Zimmerman S. Control of asthma in Canada: Failure to achieve guideline targets. Can Respir J 2001;8(Suppl A):35A-40A.

4. Global Initiative for Asthma (GINA). Global strategy for asthma management and prevention, 2006. <www.ginasthma.org> (Version current at October 20, 2008).

5. Vollmer WM, Markson LE, O'Connor E, et al. Association of asthma control with health care utilization and quality of life. Am J Respir Crit Care Med 1999;160:1647-52.

6. Juniper EF, O'Byrne PM, Guyatt GH, et al. Development and validation of a questionnaire to measure asthma control. Eur Respir J 1999;14:902-7.

7. Cockroft DW, Swystun VA. Asthma control versus asthma severity. J Allergy Clin Immunol 1996;98:1016-8.

8. Colice GL. Categorizing asthma severity and monitoring control of chronic asthma. Curr Opinion Pulm Med 2002;8:4-8.

9. Ungar WJ, Chapman KR, Santos MT. Assessment of a medicationbased asthma index for population research. Am J Respir Care Med 2002;165:190-4.

10. Boulet LP, Becker A, Bérubé D, et al. Canadian asthma consensus report. CMAJ 1999;161(11 Suppl):S1-S162.

11. Juniper EF, O'Byrne PM, Roberts JN. Measuring asthma control in group studies: Do we need airway calibre and rescue $\beta_{2}$-agonist use? Respir Med 2001;95:319-23.

12. Van Ganse E, Laforest L, Pietri G, et al. Persistent asthma: Disease control, resource utilisation and direct costs. Eur Respir J 2002;20:60-7. 


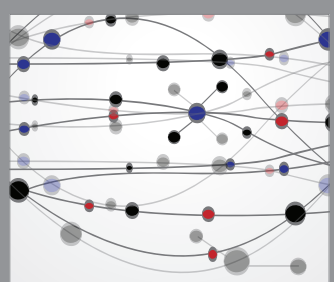

The Scientific World Journal
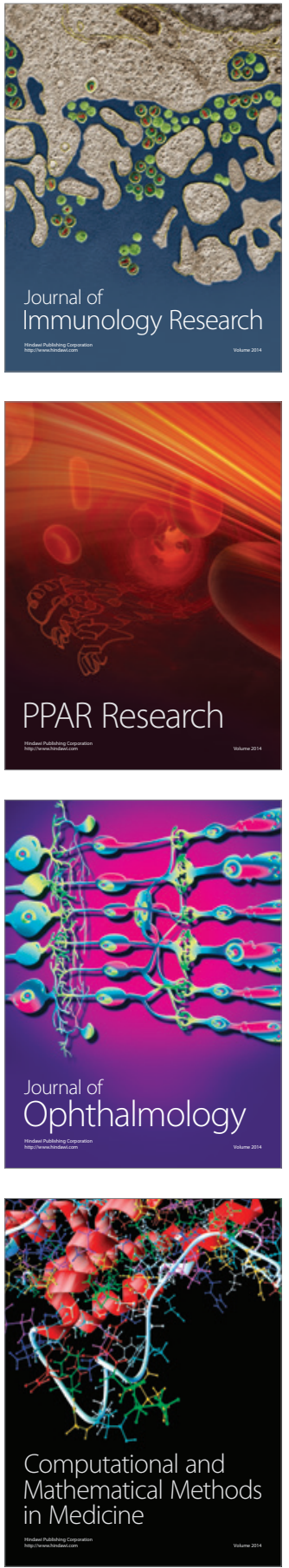

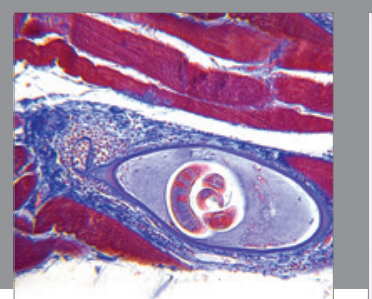

Gastroenterology Research and Practice

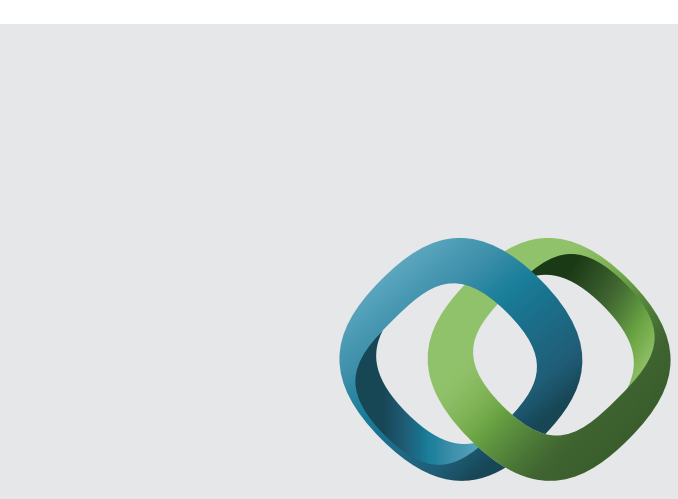

\section{Hindawi}

Submit your manuscripts at

http://www.hindawi.com
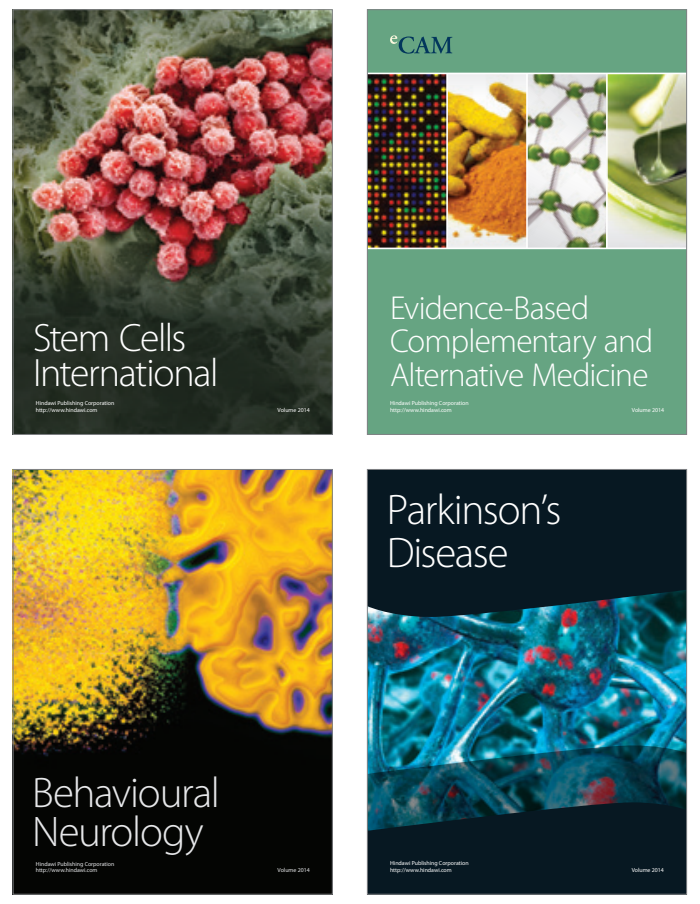
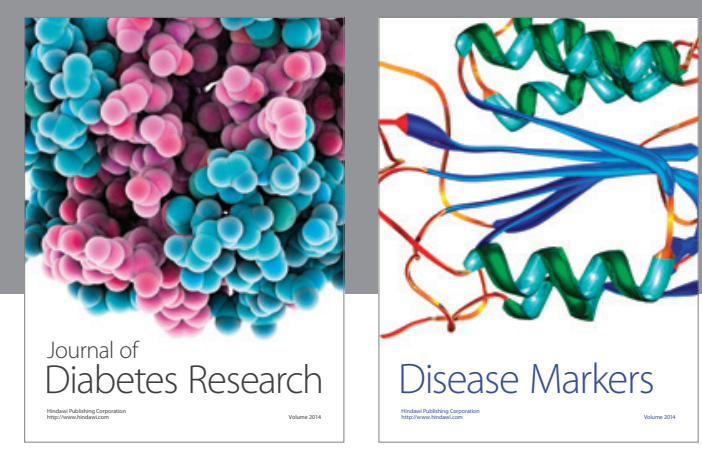

Disease Markers
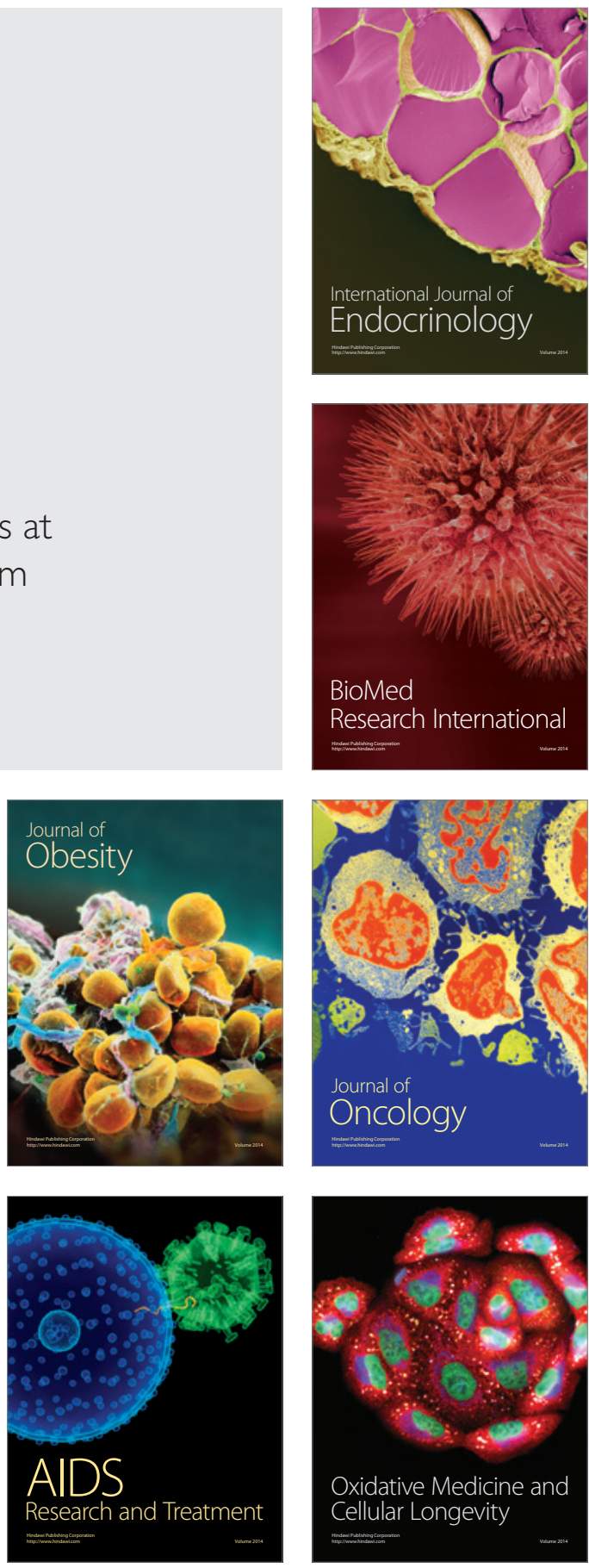